\title{
O DESEJO DA MÃE A PARTIR DO DIAGNÓSTICO DE AUTISMO
}

THE MOTHER'S DESIRE SINCE THE DIAGNOSIS OF AUTISM

EL DESEO DE LA MADRE DESDE EL DIAGNÓSTICO DEL AUTISMO

\author{
Lucimar Brandão de Oliveira*
}

\begin{abstract}
RESUMO
Este artigo busca compreender como o autismo interpela a mãe no exercício da maternidade, podendo incidir diretamente sobre o seu desejo e fragilizando a relação mãe e filho. Embora o número de casos de autismo continue aumentando desde sua descoberta, ele ainda se constitui um enigma, mesmo no campo da ciência, o que favorece a angústia materna. Assim, na tentativa de elucidar as questôes envolvidas no tema, faz-se importante traçar um breve histórico sobre o autismo e a maternidade, para além dos ideais ou padróes culturalmente estabelecidos. $\mathrm{O}$ texto ainda apresenta o olhar da psicanálise no que se refere ao desejo da mulher sobre a experiência da maternidade e sobre as soluções inventadas como forma de tratar o mal-estar resultante da relação maternal com o autismo.
\end{abstract}

Palavras-chave: Autismo. Mãe. Desejo. Psicanálise.

\begin{abstract}
This article aims to understand how autism challenges the mother in the exercise of motherhood, having the power to affect directly her desire and weaken the mother-child relationship. Although the number of cases of autism has continued to increase since its discovery, it still constitutes an enigma even in the field of science, which favors maternal distress. Thus, in an attempt to elucidate the issues involved in the theme, it is important to trace a brief history about autism and motherhood, in addition to the culturally established ideals or standards. The text still presents the view from Psychoanalysis regarding the women's desire concerning the motherhood experience, and the made-up solutions as a way to treat the uneasiness resulting from the maternal relationship with autism.
\end{abstract}

Keywords: Autism. Mother. Desire. Psychoanalysis.

* Especialista em Abordagem Psicanalítica do Autismo e Suas Conexōes (Pontifícia Universidade Católica de Minas Gerais - PUC Minas, Instituto de Educação Continuada - IEC), psicóloga. Endereço: Rua Maria Fortunata Rotheia, 418 - Paquetá, Belo Horizonte-MG, Brasil. CEP: 31330-642. Telefone: (31) 99616-3136. E-mail: lubrandao.psi@gmail.com. 


\section{RESUMEN}

Este artículo busca comprender cómo el autismo desafía la madre en el ejercicio de la maternidad, siendo capaz de enfocarse directamente en su deseo y debilitando la relación madre-hijo. Aunque el número de casos de autismo ha aumentado desde su descubrimiento, sigue constituyendo un enigma incluso en el campo de la ciencia, lo que favorece la angustia materna. Por lo tanto, en un intento de clarificar los puntos involucrados en el tema, es importante trazar una breve historia sobre el autismo y la maternidad, además de los ideales o estándares culturalmente establecidos. El texto también presenta la mirada del psicoanálisis, con respecto al deseo de las mujeres sobre la experiencia de la maternidad, y sobre las soluciones inventadas como una forma de tratar el malestar resultante de la relación materna con el autismo.

Palabras clave: Autismo. Madre. Deseo. Psicoanálisis.

\section{AUTISMO E PSICANÁLISE}

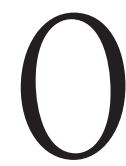
bservamos, no mundo atual, um crescente número de diagnósticos de autismo, o que, para alguns, constitui uma epidemia. Segundo dados do ano de 2019, do Centro para Controle e Prevenção de Doenças dos Estados Unidos (CDC) (Estados Unidos da América, 2019), atualmente o autismo atinge 1 a cada 68 crianças. Esse número aumentado torna o tema relevante e aponta para a importância de seu estudo no âmbito acadêmico. Ainda assim, desde o estudo de Kanner sobre o autismo, na década de 1940, o enigma diante do tema se mantém.

Segundo Laurent (2014), o aumento no número de casos de autismo é capaz de aterrorizar a espécie humana pelo fato de o espectro rondar as burocracias sanitárias. Em duas décadas, acredita-se que os casos tenham se multiplicado por dez, tornando-se uma presença insistente no mundo atual. $\mathrm{O}$ alto índice de casos também fez prosperar os estudos e tratamentos para o autismo nas mais variadas linhas teóricas, muitas delas voltadas a uma perspectiva de cura, que, por vezes, podem deixar os pais "afogados num mar de especialistas", como nos transmitem (Ferreira \& Vorcaro, 2017, p. 18).

O autismo é um assunto que está em evidência e que tem se popularizado conforme é abordado em grandes filmes, livros e na mídia em geral. Eis que o século XX rendeu-se às "proezas técnicas realizadas pelos autistas savants [prodígio]" (Laurent, 2014, p. 76). Assim, "Esse real que insiste nos dá uma ideia do que somos como discurso da civilização: aprendemos com os autistas algo que fascina, que convoca em sua diversidade" (Laurent, 2014, p. 61). Contudo o 
autor também adverte que "essa proliferação não ocorre sem provocar angústia" (Laurent, 2014, p. 62).

O autista de alto rendimento é capaz de se observar e de se descrever em termos de funcionamento, sem que haja nenhum obstáculo imaginário, o que torna seu testemunho precioso no caminho da busca pela compreensão do autismo (Laurent, 2014). Esse estudo, "ao contrário do sonho científico, que aspira à redução a uma base simples, a consideração de variações múltiplas impõe aos pesquisadores sequenciar variações genéticas atinentes a casos diferentes entre si” (Laurent, 2014, p. 77). Esse horizonte nos permite pensar que o futuro do espectro autista se encontra nos próprios sujeitos autistas, repousando na singularidade própria de cada um.

A grande oferta de tratamentos existentes, principalmente nas áreas científica e comportamental, não apagou o desejo da Psicanálise, que também tem se investido nesse estudo. Autores mais contemporâneos, desde Lacan, têm nos provido de uma vasta literatura, desenvolvida com base nos estudos da clínica com os sujeitos autistas. $\mathrm{O}$ aprofundamento nesse estudo tem nos colocado diante da incidência de uma provável quarta estrutura, a "estrutura autista", estudada e descrita por Lefort e Lefort (2017), na obra $A$ distinção do autismo. Segundo os autores, a existência dessa quarta estrutura pode ser identificada a partir de um diagnóstico diferencial entre o autismo e os casos de psicose e esquizofrenia, destacada por meio de "elementos estruturais claramente reconhecíveis. Tal estrutura viria em quarto lugar entre as grandes estruturas: neurose, psicose, perversão, autismo" (Lefort \& Lefort, 2017, p. 11).

Apesar da divergência e diversidade nas pesquisas sobre o tema, há um consenso social acerca da complexidade etiológica do autismo e da necessidade de tratamento precoce. Ainda assim, nem mesmo a ciência conseguiu, até então, desvendar esse mistério e, para Ansermet e Giacobino (2015, p. 76), o autismo foi se tornando um novo paradigma genético, capaz de levar a ciência e a genética a reconsiderar e reaprender o novo para estudá-lo. Segundo os autores "Reconsiderar os saberes após tê-los adquirido é, portanto, um passo fundamental que contribui para restaurar a humanidade e a nobreza da genética" (Ansermet \& Giacobino, 2015, p. 76). Se o discurso cientificista sobre o autismo privilegia o corpo biológico, considerando-o como uma síndrome de origem genética (Gadia, Tuchman, \& Rotta, 2004), "A Psicanálise, na sua aplicação ao autismo, não depende das hipóteses etiológicas sobre o seu fundamento orgânico" (Laurent, 2014, p. 33). Assim, há uma aposta, do ponto de vista da Psicanálise, de que tanto a compreensão do autismo quanto a direção do tratamento só serão encontradas na singularidade de cada sujeito. Nesse sentido, 
Ribeiro (2013) ressalta que a busca pelo sujeito singular contrapõe o discurso universalizante da ciência.

Ferreira e Vorcaro (2017) nos alertam que a Psicanálise segue na contramão desse intuito de uma consolidação de bases genéticas únicas, no que diz respeito ao autismo, e sim caminha ao encontro do sujeito e de sua singularidade. Para as autoras, é necessário pensar além das discussões sobre o que é o autismo e suas causas, além "das propostas de tratamento para todos e protocolos de conduta, aceitando o enigma que cada sujeito faz e seu modo de estar no mundo" (Ferreira \& Vorcaro, 2017, p. 71, grifo das autoras).

A investigação sobre o autismo dos últimos anos, apoiada por testemunhos de diversos sujeitos autistas, por meio de seus próprios relatos e também dos relatos de seus pais sobre a convivência familiar, amplia a oportunidade de pensarmos o drama familiar que o diagnóstico de autismo pode causar nas relações de mães e filhos. Muitas mães escrevem seus textos e livros, inspiradas, muitas vezes, por sua história de superação à devastação inscrita pelo diagnóstico de autismo do filho. O desejo materno deverá encontrar lugar entre o filho idealizado e a criança real advinda do autismo, e certamente se modificará. Como para o autismo, faz-se necessária a compreensão de cada caso de maneira singular, a relação de desejo materno diante do autismo também necessita ser singular.

\section{DESEJO E MATERNIDADE}

A maternidade é um tema complexo e vem sendo estudado por diferentes áreas do conhecimento ao longo dos anos. Promover uma reflexão a respeito do lugar da maternidade no desejo da mulher contemporânea pode ajudar a compreender como o autismo interfere nesse desejo. Durante décadas, a maternidade se consolidou como sendo o destino das mulheres, mas, atualmente, a maternidade consiste apenas, em uma das possibilidades de escolha da mulher e não seu destino natural (Meira, 2010). Pensar a maternidade com base na Psicanálise, propõe, desmistificar o "lugar de mãe" como lugar do paraíso ou do instinto, atrelando a maternidade muito mais à subjetividade e à experiência particular de vida de cada mulher. Nesse sentido, Alvarenga argumenta que, não há harmonia preestabelecida entre uma mãe e uma criança e que "a maternidade é um campo aberto ao imprevisto e à contingência" (Alberti \& Alvarenga, 2015, p. 9).

A maternidade, atualmente, desloca a figura da mãe da posição de nenhum envolvimento com a criança para uma posição de responsabilidade, praticamente total, sobre a criação dos filhos. A esse respeito, Campos descreve que, na atualidade, "A mulher é tida como a única responsável pela criação dos filhos" 
(Campos, 2016, p. 156). Solano-Suárez (2015) adverte-nos que a real experiência da mulher em relação à maternidade pode não coincidir com seu desejo ou idealização. Não existe, portanto, uma fórmula programada, que leve a mãe a encontrar seu dom natural ao ser mãe. Solano-Suárez (2015) salienta a ausência de uma bula pronta, o que leva a mulher a ter de "inventar, a cada momento, sua resposta materna” (p. 84). Para a autora, a experiência de ser mãe é algo que escapa à palavra, é da ordem daquilo que é impossível de se nomear.

O amor materno não é programado, o encontro de uma mãe com seu filho é suscetível de não despertar nela um elã maternal e que, para estar em condiçôes de assumir o estado "de ser mãe", uma mulher deve encarar aquilo que o nascimento do filho desvela como decorrendo do impossível (Solano-Suárez, 2015, p. 76).

Lacan, em seu ensino, comunica-nos que a criança vai se inscrever na relação da mulher com sua falta como o falo que iria preenchê-la. "Se a mulher encontra na criança uma satisfação, é, muito precisamente, na medida em que encontra nesta algo que atenua, mais ou menos bem, sua necessidade de falo, algo que o satura" (Lacan, 1956-1957/1995, p. 71). " "O falo não é o pênis. Ele aqui é tomado em sua função imaginária, como objeto que falta à mulher e que viria a preenchê-la" (Ribeiro, 2013, p. 53). O filho, ao ser tomado como um atributo fálico, inscreve-se como significante do desejo materno, embora esse acontecimento não tamponará o apetite fálico da mãe como mulher. Seu desejo não cessará, já que o desejo é movimento e continuará reinscrevendo-se durante toda a sua vida.

Atualmente, o desejo pela maternidade, de ter um filho como idealização simbólica do falo, não necessariamente precisa acontecer, pois a mulher pode realizar-se por meio de outros objetos. A mulher dos dias atuais não é mais a mesma mulher dos tempos de Freud (Couto, 2015). As mudanças culturais da época incidem inclusive sobre seu desejo. A mulher das últimas décadas adquiriu maior liberdade de escolha diante das mudanças socioculturais e da transformação de seu lugar tanto na sociedade como no mercado de trabalho. Assim, Campos (2016, p. 156) descreve que as mulheres atuais "experimentam conflitos de toda ordem entre a maternidade e o trabalho".

Se algumas mulheres encontram na maternidade a felicidade e uma identificação insubstituível, um destino desejado e a realização pessoal, por outro lado, existem aquelas cujo desejo está para além dos cuidados maternos, almejam mais independência e possibilidades de se reafirmarem profissionalmente (Badinter, 2011).

1 A primeira data indica o ano de publicação da obra, e a segunda, a edição consultada pelo autor, a qual somente será pontuada na primeira citação da obra no texto. Nas seguintes, será registrada apenas a data de publicação original. 
O desejo materno se vê impossibilitado de realizar-se no autismo. Uma vez que a criança autista não se sujeita a ser objeto de desejo do Outro. $\mathrm{O}$ autista se fecha à demanda do Outro. Não cede a ser seu objeto, seu desejo. O autista "defende-se da figura do absoluto sendo o absoluto. [. . . F Fazendo-se ativamente de inerte ou de máquina significante, não acolhe demandas nem apela para anular o Outro" (Soler, 1999, p. 229). Vorcaro, defende a ideia de que essas crianças estabelecem os meios de se defender do Outro invasivo e demandante construindo uma "indiferença ao que lhe faz exterioridade, que a assepsia ao princípio da representação significante realiza" (Vorcaro, 2008, p. 32). Também para Nominé (2001), a posição autística é uma defesa contra uma presença insuportável, uma "intrusão de um [. . .] tirano absoluto" (p. 13).

A recusa do autista, portanto, é também à mãe, ao seu olhar, carinho, amor e tudo mais que ela the oferece. Um ser que recusa qualquer oferta de afeto, de contato, como pode a mãe o desejar? Muitas mães, diante dessa recusa, sentemse devastadas e desistem da criança que não corresponde a seu desejo.

\section{AUTISMO, DIAGNÓSTICO E MATERNIDADE}

O diagnóstico de autismo pode ser angustiante para a mãe. Sobre isso, Werner (2016) alerta para a angústia da mãe a partir do diagnóstico de autismo do filho. Para a autora, o encontro com o desconhecido no autismo é um dos fatores que provocam maior apreensão na mãe. Para Freud (1925/1996, p. 131), a angústia é uma reação a uma situação de perigo remediada pelo "eu", emitido no sentido de alertar o sujeito para a situação de desamparo. Para Lacan (1962-1963/2005), em $O$ seminário, livro 10: a angústia, a angústia é sinal do real, "de uma forma irredutível sob a qual esse real se apresenta na experiência" (p. 178). A angústia produzida pelo enigma proposto pelo autismo advém "a partir de uma recusa radical, seja do contato afetivo, de tomada da fala, dos movimentos repetitivos, enfim, da recusa inicial do campo de trocas simbólicas com o Outro" (Vidigal, 2018, p. 19).

Silva, Gaiato e Reveles (2012) elaboram a ideia de que o lar jamais será o mesmo após a chegada de uma criança com autismo e descrevem que o diagnóstico é um momento crítico e pode soar como uma verdadeira "sentença de morte para a maioria dos pais" (p. 207). Uma criança autista geralmente nasce bem e não apresenta diferenças físicas ou visíveis facilmente. Contudo a criança parece não se interessar pelo mundo, isolando-se em seu mundo singular. $\mathrm{O}$ isolamento do filho e a falta de interesse dele pelas pessoas, inclusive pela mãe, no mínimo, produz uma série de questionamentos que angustiam. Mello (2013) destaca que muitas mães, ao descobrirem o autismo do filho, sentem-se como 
ela se sentiu: com mil perguntas e nenhuma resposta. Ela ainda comenta como o futuro tornou-se assustador e intimidador.

Aqueles dias eram de interrogações. Não sabíamos interpretar o seu olhar, suas frustrações e nem sabíamos o que fazer quando ele gritava sem razão aparente. Os estranhos me olhavam com censura. [. . .] Ele gritava quando eu tentava abraçá-lo e fugia dos nossos carinhos (Mello, 2013, p. 54).

A revista Reme publicou o artigo Convivendo com a criança autista: sentimentos da família (Rodrigues, Fonseca, \& Silva, 2008), que contém alguns exemplos desses sentimentos. São frases como "ficamos perdidos, desorientados, tristes e com medo do futuro"; "ele não era do jeito que eu esperava, hoje já acostumei"; "eu preferia que tivesse nascido normal, mas Deus quis assim, fazer o quê, né?". Mello (2013) relata um sentimento de luto resultante do distanciamento do filho, como se muralhas a separasse dele. "Eu tentava conversar, interagir e, de alguma forma, entender o seu universo e ser parte dele. Meu grande medo era que ele ficasse aprisionado para sempre naquele mundo que eu não conseguia tocar" (Mello, 2013, p. 55). Com o diagnóstico, surgem muitas perguntas as quis os médicos não conseguem responder às mães, como "Meu filho vai falar? Ele vai ser independente? O que posso esperar do futuro dele"? (Werner, 2016, p. 30).

Barnett (2013) relata, em seu livro, sua angústia ante o real do autismo. "Nosso menino, um dia afetuoso, não falava conosco, não nos abraçava, não dizia que nos amava. Nem olhava para nós, a menos que acontecesse de um de nós estar no caminho de uma das sombras que ele observava" (Barnett, 2013, p. 51). Sobre o diagnóstico, ela nos conta: "Penso nesse ano como o ano em que vivi dentro do diagnóstico" (Barnett, 2013, p. 42). Essa mãe define o sentimento ante o diagnóstico como "a corrida contra o tempo", o que pode, por vezes, minar as esperanças dos pais diante de tantos investimentos de tempo e de dinheiro e poucas respostas satisfatórias:

Você come, respira e dorme autismo. Luta contra o autismo a cada momento, desperto e quando adormece sabe que poderia - que deveria - ter feito mais. Como existem muitas provas de que a melhora depende da quantidade de intervenção que a criança recebe antes dos cinco anos, a vida com uma criança autista é uma constante corrida contra o relógio para fazer mais, mais, mais (Barnett, 2013, p. 41).

Couto (2015), descreve que, entre os impasses que o autismo provoca na vida de uma mãe, encontra-se a dificuldade de se incluir, como um Outro, na vida da criança autista. Em geral, as mães revelam o impacto sofrido na subjetividade materna, em razão do diagnóstico de autismo do filho, que escancara uma 
criança real demais para a mãe, provocando uma devastação e um desamparo. O real do autismo interpela a mulher no cerne de seu ser mãe, e ela se põe a trabalho a partir de então, normalmente para a vida toda. Como cada autista é um, cada mãe também é uma e, portanto, para a Psicanálise, há a importância de se escutar caso a caso, para ser possível escapar dos discursos que se atentam apenas para a doença, pois "a criança não é o transtorno, ainda que esteja no espectro autista” (Silva, Gaiato, \& Reveles, 2012, p. 207).

Geralmente são as mães que mais se envolvem no tratamento e no acompanhamento do filho autista. $\mathrm{Na}$ maior parte dos casos, são elas que percebem ou que detectam os primeiros sinais característicos do autismo, em sua convivência diária com a criança. $\mathrm{O}$ seu surgimento leva o contexto familiar a viver rupturas ou interromper sonhos e planos, conduzindo à readequação quanto às atividades do dia a dia. Mas, ainda que o autismo introduza um filho diferente do sonhado pela mãe, Werner (2016) alerta que os sonhos não se perdem, podendo ser reescritos. A autora destaca que a mãe continua sonhando, porém sonhos mais simples, tornando-se capaz de absorver, de maneira mais humana, as diferenças e buscando soluções alternativas para sua nova perspectiva de vida.

O autismo entra na vida da mulher como uma importante contingência, podendo alterar o desejo da mãe sobre esse filho que recusa seu investimento libidinal, podendo fazer instaurar entre os dois um abismo. Esse abismo pode criar para a própria mãe um enigma sobre seu desejo. Assim, como responder à questão sobre o lugar do desejo da mãe a partir do diagnóstico de autismo? A psicanalista Bartyra Ribeiro de Castro exprime belas considerações a esse respeito no prefácio do livro Quem é meu filho [. . . ]? (Castro, 2017). Segundo ela, é especial ver "um filho se revelando a partir da coragem de seus pais de se haverem com a queda de seus ideais e com a revelação de novas realidades" (Castro, 2017, p. 6). Os pais de filhos autistas precisam encontrar, diante desse diagnóstico que pode ser avassalador, um novo olhar que faz muro contra a angústia, apostando em descobrir em seus filhos uma forma singular de amar. Os autistas têm a difícil tarefa de encontrar um lugar no desejo de seus pais e, como todos os outros filhos, jamais corresponderão às suas expectativas, pela simples impossibilidade dessa tarefa. O olhar delicado de consentimento da mãe que recebeu esse diagnóstico pode abrir caminhos com base no entendimento de que "um diagnóstico não é uma sentença, mas uma orientação. Um caminho de tratamento. Pode comportar uma ajuda, um esclarecimento" (Castro, 2017, p. 7).

Em meio à turbulência evocada pelo autismo, a escrita tem se popularizado entre as mães como forma de solução em sua invenção de ser mãe. A escrita 
propicia que mulheres inventem para si uma condição de mãe, ainda que esta esteja fora da norma, fora dos padrões. Livros e blogs revelam como é ser mãe de uma criança que escapa ao previsível e desafia o saber preestabelecido. Dessa forma, as mães produzem um afastamento de seus fantasmas e ainda nomeiam a sua criança nesse mundo. A motivação de cada mãe quanto à escrita leva em conta a subjetividade de cada caso. A função da escrita para essas mães pode ser várias, mas há a invenção de um saber sobre a criança e também a inscrição da criança no campo literário, seja ele científico ou apenas biográfico (Couto, 2015).

Ferreira e Vorcaro (2017) nos ajudam a pensar como a escrita de mães pode nos levar à compreensão de sentimentos e também à identificação de estratégias e invenções a fim de tratar esse real que o autismo constitui. A escrita das mães de autistas testemunha o desabafo de mães quanto à sua difícil missão, sua luta diária, e o mais importante: testemunham também suas conquistas! Muitas mães têm nessa ferramenta a oportunidade de expor suas experiências, suas realizações e suas alegrias, que podem servir como suporte e apoio a muitas outras mães que ainda estejam vivendo o infortúnio do diagnóstico recente de autismo. O importante a se considerar é o quanto essa escrita promove alívio ao que angustia essa mãe. Uma mãe elabora a escrita para si assim: "E o futuro parece, novamente, promissor. E o autismo, menos assustador" (Werner, 2016, p. 47). E então ela escreve, "porque escrever, assim como o ombro do companheiro, também ajuda a curar". Além de ser uma das soluções inventadas pela mãe para se libertar das amarras impostas pelo autismo, a escrita pode despertar outras famílias sobre o campo aberto de possibilidades existente em torno do caos, como relatou Barnett (2013).

Receber, portanto, um diagnóstico de autismo para um filho pode ser impactante, pois as dificuldades que acometem o sujeito nesses casos podem fragilizar o desejo da mãe na vivência da maternidade. Como afirma Jerusalinsky (2007), a maternidade é afetada quando o filho apresenta alguma limitação significativa, pois a mãe percebe a diferença existente entre a criança desejada e a criança real. Mas que fique claro também que a mãe pode criar para si saídas inusitadas e soluções infindáveis, a fim de dar lugar ao amor, entendendo que o filho é o mesmo filho desejado antes do autismo. Não é o filho idealizado na gestação, mas que encontra, na superação da frustração, um lugar, lugar de infinitas possibilidades de amor. 


\section{CONSIDERAÇÕES FINAIS}

Conforme exposto, a maternidade engloba uma complexidade que se torna ainda maior em seu encontro com o autismo, torna-se um grande desafio. $\mathrm{O}$ trajeto percorrido neste estudo me faz concluir que a mãe desempenhará, a partir do diagnóstico, um trabalho de inventar-se como mãe de um autista, uma mãe sob medida que se torna possível, mesmo diante do impossível do autismo. A invenção de um caminho próprio, ou seja, um trabalho que ajuda a inventar para si um modo de viver e de permitir ao filho ser quem ele é. Faz-se importante lembrar que esse trabalho só será possível se a mãe enxergar o filho para além das lentes do autismo e de tudo o que ele engloba, entendendo que ele continua ali, diante dela, não necessitando de nenhum conserto.

O discurso cientificista baseia-se nos critérios estabelecidos pelo DSM (American Psychiatric Association, 2013), para definição e diagnóstico, buscando esclarecer o mistério em torno do autismo com base no corpo biológico. Já a Psicanálise se propõe à análise do caso a caso, buscando a causação do sujeito autista para além do autismo em si. A Psicanálise, principalmente numa visão de autores mais contemporâneos, tem apostado nas construções de soluções do próprio sujeito diante das suas singularidades, a fim de escapar do sofrimento, e essa aposta também se dirige às mães.

Muitas mães nessa condição têm encontrado a escrita como uma saída que propicia a invenção de uma condição de mãe. Em seus livros, a escrita tem sido capaz de afastá-las dos seus fantasmas e ainda propicia que inscrevam sua criança no mundo, protegendo-a e valorizando-a. A escrita é capaz tratar um mal-estar, muitas vezes solitário, produzindo alívio da tensão materna vivenciada como consequência desse encontro, entre o ser mãe e o autismo.

Ao longo do desenvolvimento deste estudo, buscou-se atentar para o aspecto do sujeito desejante, que não se refere às simples representaçóes de papéis, que aponta para a ótica da singularidade na criação própria de soluçôes baseadas num trabalho desempenhado. Embora a maternidade tenha sido um ponto central desse estudo, muito longe de negar sua importância nem de generalizar o termo, houve, sim, a intenção de provocar considerações sobre ela, que excedam a lógica dos cuidados. Assim, não cabe a afirmação de que toda mulher deseja ser mãe, tampouco de que a maternidade se torna impossível diante do diagnóstico de autismo. Pôde-se compreender que os desdobramentos do desejo constituem um processo singular, mas que encontrará, cada mãe à sua maneira, sua forma de fazer com essa situação. 
As mães de filhos autistas, no tocante a seu desejo, só poderão ser pensadas uma a uma. Assim, é possível refletir que nem sempre o desejo de cada mulher estará atrelado à maternidade, tampouco se poderá afirmar que ele desaparecerá diante da condição imprevista do autismo. Como visto, o desejo não cessa, ele se movimenta constantemente, e a direção dessa movimentação dependerá exclusivamente do olhar de cada mulher à sua própria condição em relação a seu filho. A questão do desejo na maternidade atravessada pelo autismo, na perspectiva psicanalítica, está para além dos avanços do discurso da ciência, das modificações da sociedade e da cultura. Portanto, para uma mãe, sustentar o desejo diante desse diagnóstico é uma tarefa que requer muito trabalho e implicação subjetiva, uma construção que envolve o singular do desejo de cada uma, na contramão de um saber universal que as nomeie ou defina. 


\section{REFERÊNCIAS}

Alberti, C., \& Alvarenga, E. (2015). Ser mãe, mulheres psicanalistas falam da maternidade. Belo Horizonte: Escola Brasileira de Psicanálise.

American Psychiatric Association (2013). Diagnostic and statistical manual of mental disorders (DSM-V). Washington: APA. Recuperado a partir de http://www.dsm5.org/

Ansermet, F., \& Giacobino, A. (2015). Autismo: a cada um o seu genoma. Petrópolis: KBR Digital.

Badinter, E. (2011). O conflito: a mulher e a mãe. Rio de Janeiro: Record.

Barnett, K. (2013). Brilhante: a inspiradora história de uma mãe e seu filho gênio e autista. Rio de Janeiro: Jorge Zahar.

Campos, S. (2016). Fragmentos de Narrativas ficcionais. In Campos, S. Obesidade em Jovens: frustração, anguistia, gula e culpa: a lógica psicanalítica do ganho de peso. (pp. 154-177). Belo Horizonte: Escola Brasileira de Psicanálise.

Castro, B. R. (2017). Prefácio. In A. Gonring, \& D. Dotzauer (Orgs.), Quem é meu filho...?: autismo, psicanálise e arte. Vitória: Pipa.

Couto, M. P. (2015). Quais os impasses para a criança se inscrever no outro hoje? Curinga, 40(1), 145-161.

Estados Unidos da América. (2019). Division of Birth Defects, National Center on Birth Defects and Developmental Disabilities, Centers for Disease Control and Prevention. Data \& statistics on autism spectrum disorder. Washington: CDC. Recuperado a partir de https://www.cdc.gov/ncbddd/autism/data.html

Ferreira, T., \& Vorcaro, A. (2017). Tratamento psicanalitico de crianças autistas: diálogo com múltiplas experiências. Belo Horizonte: Autêntica.

Freud, S. (1925/1996). Inibiçōes, sintomas e ansiedade. In J. Salomão (Trad.), Edição standard brasileira das obras psicológicas completas de Sigmund Freud. (Vol. 20, pp. 79-168). Rio de Janeiro: Imago, 1996. (Publicado originalmente em 1925).

Gadia, C. A., Tuchman, R., \& Rotta, N. T. (2004). Autismo e doenças invasivas de desenvolvimento. Jornal de Pediatria, 80(2, supl.), S83-S94. 
Jerusalinsky, A. (2007). Psicanálise e desenvolvimento infantil. (4a ed.). Porto Alegre: Artes e Ofícios.

Lacan, J. (1956-1957/1995). O seminário: livro 4: a relação de objeto. Rio de Janeiro: Jorge Zahar, 1995. (Publicado originalmente em 1956-1957).

Lacan, J. (1962-1963/2005). O seminário: livro 10: a angústia. Rio de Janeiro: Zahar, 2005. (Publicado originalmente em 1962-1963).

Laurent, E. (2014). A batalha do autismo: da clínica à política. Rio de Janeiro: Zahar.

Lefort, R., \& Lefort, R. (2017). A distinção do autismo. Belo Horizonte: Relicário.

Meira, A. C. (2010). Dos impasses da maternidade a uma verdade indizivel: uma leitura psicanalítica sobre a feminilidade. (Dissertação de Mestrado). Universidade Federal da Bahia, Faculdade de Filosofia e Ciências Humanas, Salvador.

Mello, J. C. (2013). Esdras: a história de um menino autista. Almirante Tamarandé: Jocum Brasil.

Nominé, B. (2001). O autista: um escravo da linguagem. Marraio, 2, 11-23.

Ribeiro, J. M. L. C. (2013). A criança autista em trabalho. (2a ed.). Rio de Janeiro: 7 Letras.

Rodrigues, L. R., Fonseca, M. O., \& Silva, F. F. (2008). Convivendo com a criança autista: sentimentos da família. Reme, Revista Mineira de Enfermagem, 12(3). Recuperado a partir de http://www.reme.org.br/artigo/detalhes/272

Silva, A. B. B., Gaiato, M. B., \& Reveles, L. T. (2012). Mundo singular: entenda o autismo. Rio de Janeiro: Objetiva.

Solano-Suárez, E. (2015). Maternidade blues. In C. Alberti, \& E. Alvarenga. (Orgs.), Ser mãe: mulheres psicanalistas falam da maternidade. Belo Horizonte: Escola Brasileira de Psicanálise.

Soler, C. (1999). Autismo e paranoia. In S. Albert (Org.), Autismo e esquizofrenia na clínica da esquize. (pp. 219-232). Rio de Janeiro: Marca D’água.

Vidigal, C. (2018). O cérebro de Hugo. In E. Alvarenga, \& S. Laia (Orgs.), O que é o autismo, hoje? Belo Horizonte: Escola Brasileira de Psicanálise. 
Vorcaro, A. M. R. (2008). A angústia nos autismos e nas psicoses da infância. Reverso, 30(56), 27-34.

Werner, A. (2016). Lagarta Vira Pupa: a vida e os aprendizados ao lado de um lindo garotinho autista. São Paulo: CR8. 